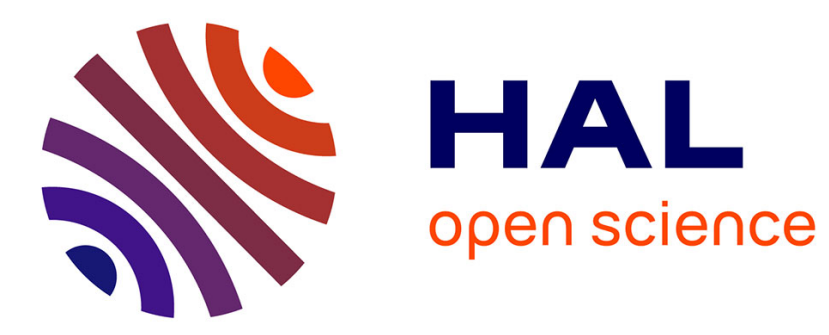

\title{
Electronic and vibrational polarizabilities of the twenty naturally occurring amino acids
}

Salvatore Millefiori, Andrea Alparone, Arcangelo Millefiori, Angelo Vanella

\section{To cite this version:}

Salvatore Millefiori, Andrea Alparone, Arcangelo Millefiori, Angelo Vanella. Electronic and vibrational polarizabilities of the twenty naturally occurring amino acids. Biophysical Chemistry, 2007, 132 (2-3), pp.139. 10.1016/j.bpc.2007.11.003 . hal-00501690

\section{HAL Id: hal-00501690 \\ https://hal.science/hal-00501690}

Submitted on 12 Jul 2010

HAL is a multi-disciplinary open access archive for the deposit and dissemination of scientific research documents, whether they are published or not. The documents may come from teaching and research institutions in France or abroad, or from public or private research centers.
L'archive ouverte pluridisciplinaire HAL, est destinée au dépôt et à la diffusion de documents scientifiques de niveau recherche, publiés ou non, émanant des établissements d'enseignement et de recherche français ou étrangers, des laboratoires publics ou privés. 


\section{Accepted Manuscript}

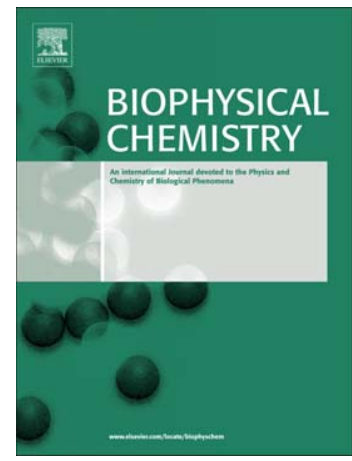

Electronic and vibrational polarizabilities of the twenty naturally occurring amino acids

Salvatore Millefiori, Andrea Alparone, Arcangelo Millefiori, Angelo Vanella

PII: $\quad$ S0301-4622(07)00270-0

DOI: $\quad$ doi: $10.1016 / j . b p c .2007 .11 .003$

Reference: $\quad$ BIOCHE 5040

To appear in: Biophysical Chemistry

Received date: $\quad 8$ June 2007

Revised date: $\quad 31$ October 2007

Accepted date: 1 November 2007

Please cite this article as: Salvatore Millefiori, Andrea Alparone, Arcangelo Millefiori, Angelo Vanella, Electronic and vibrational polarizabilities of the twenty naturally occurring amino acids, Biophysical Chemistry (2007), doi: 10.1016/j.bpc.2007.11.003

This is a PDF file of an unedited manuscript that has been accepted for publication. As a service to our customers we are providing this early version of the manuscript. The manuscript will undergo copyediting, typesetting, and review of the resulting proof before it is published in its final form. Please note that during the production process errors may be discovered which could affect the content, and all legal disclaimers that apply to the journal pertain. 


\section{Electronic and vibrational polarizabilities of}

\section{the twenty naturally occurring amino acids}

Salvatore Millefiori, ${ }^{\mathrm{a}, \mathrm{b} *}$ Andrea Alparone, ${ }^{\mathrm{b}}$ Arcangelo Millefiori, ${ }^{\mathrm{b}}$

Angelo Vanella, ${ }^{c}$

${ }^{a}$ Dipartimento di Scienze Chimiche e Facoltà di Farmacia, Università di Catania, Viale A. Doria 8, Catania 95125, Italy

${ }^{b}$ Dipartimento di Scienze Chimiche,Università di Catania, Viale A. Doria 8, Catania 95125, Italy

${ }^{c}$ Dipartimento di Chimica Biologica,Chimica Medica e Biologia Molecolare, Facoltà di Farmacia, Università di Catania, Viale A. Doria 6, Catania 95125, Italy

Corresponding author

\section{Salvatore Millefiori}

Address: Department of Chemical Sciences and Faculty of Pharmacy, University of Catania Viale A. Doria 8, Catania 95125, Italy

Phone: +39957385084

Fax: +39 95580138

Email: smillefiori@unict.it

Text pages: 17

Number of tables: 6

Number of illustrations: 6 


\section{Abstract}

The geometries, relative energies, gas-phase static and dynamic dipole polarizabilities of the two most stable neutral forms and of the zwitterionic form of the twenty naturally occurring amino acids have been obtained by Density Functional and conventional ab initio HatreeFock theories using correlation consistent basis sets. Mean electronic polarizabilities $\left(<\alpha^{\mathrm{e}}>\mathrm{s}\right)$ are encompassed in the 40-160 a.u. range and are little dependent on the amino acid framework conformation, structure and conformation. The relation between $\left\langle\alpha^{\mathrm{e}}\right\rangle$ and the number of electrons in the molecule makes to classify the amino acids as one of the most polarizable family of compounds. Calculated $\left\langle\alpha^{\mathrm{e}}\right\rangle$ values of the neutral forms linearly relate to the molecular volume and molecular hardness as well as, rather unexpectedly, with the experimental values in water solution, where amino acids are known to be in a zwitterionic form. Vibrational polarizabilities amount to 15-45 a.u.. They come essentially from the lowfrequency angular deformation modes of the $-\mathrm{OH}$ and $-\mathrm{NH}_{2}$ groups.

Keywords: amino acids; electronic polarizability; vibrational polarizability; DFT; MP2 calculations. 


\section{Introduction}

The molecular polarizability is the response of the electronic structure of a system to an external electric field $\mathrm{F}$, owing to the molecular dipole moment $\mu$ varies as

$\mu_{\mathrm{i}}(\mathrm{F})=\mu_{\mathrm{i}}(0)+\alpha_{\mathrm{ij}} \mathrm{F}_{\mathrm{j}}+1 / 2 ! \beta_{\mathrm{ijk}} \mathrm{F}_{\mathrm{j}} \mathrm{F}_{\mathrm{k}}+1 / 3 ! \gamma_{\mathrm{ijk}} \mathrm{F}_{\mathrm{j}} \mathrm{F}_{\mathrm{k}} \mathrm{F}_{1} \ldots$

where $\mu(0)$ is the dipole moment value in the absence of field, and $\alpha, \beta$ and $\gamma$ define polarizability, first and second hyperpolarizabilities, respectively. Thus the components of the polarizability tensor are obtained as $\alpha_{\mathrm{ij}}=\left(\partial \mu_{\mathrm{i}} / \partial \mathrm{F}\right) \mathrm{F} \rightarrow 0$. Polarizability has a volume dimension and depends on the shape and size of the molecule. Three contributions determine $\alpha$ : an electronic contribution, $\alpha^{\mathrm{e}}$, due to the electronic polarization, a vibrational one, $\alpha^{\mathrm{v}}$, due to the 
molecular relaxation and, in a floppy molecule, a contribution due to the permanent dipole moment, $<\mu^{2}>_{0} / \mathrm{kT}$, where $\left\langle\mu^{2}>_{0}\right.$ is the average of the square of the projection of the permanent dipole moment on the axis of the electric field [1].

Experimentally the mean value $\left\langle\alpha>=1 / 3\left(\alpha_{\mathrm{xx}}+\alpha_{\mathrm{yy}}+\alpha_{\mathrm{zz}}\right)\right.$ is usually determined from the refractive index or from dielectric measurements [2], while $\alpha^{\mathrm{V}}$ can be obtained from infrared intensities [2-4]. Theoretically $\langle\alpha\rangle$ can be obtained accurately by means of Density Functional Theory (DFT) and wave function-based methods, provided that sufficiently flexible basis sets are used including diffuse and polarization functions, and that electron correlation corrections are taken into account. Owing to its intrinsic significance, $\alpha$. is an important factor which characterizes many physical-chemical properties such as dielectric properties [5,6], polarizable force field [7] and QSAR studies for chemical-biological interactions [8]. Relative $\alpha$ value is a descriptor of relative molecular stability. The present paper reports the results of gas phase theoretical determination of dipole moments, electronic and vibrational static and dynamic (frequency-dependent) polarizabilities of the twenty naturally occurring amino acids, carried out by conventional ab initio Hartree-Fock (HF), DFT and second order Møller-Plesset Perturbation Theory (MP2) correlated methods. Neutral forms of the amino acid are considered, which are the stable ones in the gas phase. There are not many papers concerning the experimental and/or theoretical determination of the amino acids polarizability. Khanarian and Moore [9] obtained the molar Kerr constant and dipole moment of amino acids in water and deduced from the molar refraction $\mathrm{R}_{\mathrm{m}}$ reported by Meekin et al. [10] the sum $\left(\alpha_{x x}+\alpha_{y y}+\alpha_{z z}\right)$ of the $\alpha_{i j}$ components. Only very recently ab initio theoretical computations of amino acids polarizabilties have been addressed. Hansen et al. [11] reported the frequency-dependent polarizabilities of the twenty essential amino acids calculated by HF and point dipole interaction (PDI) models. Tulip and Clark [12] calculated 
polarizability tensors of alanine, leucine, isoleucine and valine using plane wave pseudopotential methods. Finally Swart et al. [13] used time-dependent DFT (TD-DFT) computations to obtain molecular polarizabilities of the twenty amino acids residues.

\section{Computational procedure}

The geometries of the investigated amino acids conformers were obtained by DFT computations using the B97-1 functional [14] with the cc-pVDZ correlation consistent basis set. Relative energies were obtained at HF, MP2 and DFT-B97-1 levels using cc-pVDZ and aug-cc-pVDZ basis sets, and were corrected for zero-point vibrational energy (ZPVE) contribution. Harmonic vibrational analysis, carried out at B97-1/cc-pVDZ level, showed that the reported structures are true minima in the potential energy surface. HF dipole moments and static dipole polarizabilities were computed analytically within the TD-HF using the augcc-pVDZ basis set. Electron correlation contributions were introduced by MP2 and DFT-B971 methods. Correlated polarizabilities values were computed by means of the finite field (FF)

procedure following Kurtz at al. [15] using an electric field strength of 0.005 a.u.. The accuracy of this approach was checked at HF level by comparing $\alpha^{\mathrm{e}}$ values obtained by both analytical and FF procedures. Frequency-dependent polarizabilities were evaluated at B971/aug-cc-pVDZ level at the experimental laser radiation energy of 0.0788 a.u. $(\lambda=578 \mathrm{~nm})$. The vibrational contribution to $\alpha$ was evaluated under the double harmonic oscillator approximation with the sum-over-modes expression [16]:

$$
\alpha_{i j}^{v}=\sum_{a}^{3 N-6} \frac{\left(\frac{\partial \mu_{i}}{\partial Q_{a}}\right)_{0}\left(\frac{\partial \mu_{j}}{\partial Q_{a}}\right)_{0}}{\omega_{a}^{2}}
$$


where $\omega_{\mathrm{a}}$ is the circular vibrational frequency of the ath normal mode $\mathrm{Q}_{\mathrm{a}}$ and $\partial \mu_{\mathrm{i}} / \partial \mathrm{Q}_{\mathrm{a}}$ is the partial derivative of the $\mathrm{i}$-component of $\mu$ with respect to $\mathrm{Q}_{\mathrm{a}}$ evaluated at the equilibrium geometry. Static $\alpha^{\mathrm{v}}$ values were calculated at DFT-B97-1 level with the cc-pVDZ basis set. All computations were performed with GAUSSIAN-03 [17] and GAMESS [18] series of programs.

\section{Results and discussion}

\subsection{Geometries and relative energies}

Accurate $\alpha$ values require accurate molecular geometries. The molecular parameters of the investigated amino acids were optimized at DFT-B97-1/cc-pVDZ level. The complete set of the optimized geometrical parameters is available on request by the authors. Two molecular configurations of the $\mathrm{NH}_{2}-\mathrm{CH}-\mathrm{COOH}$ backbone were taken into consideration, which, by reference to glycine molecule are (Fig. 1): form 1 which bears a bifurcated $\mathrm{NH}_{2}-----\mathrm{O}=\mathrm{C}$ hydrogen bonding, and form 2 which bears a single $\mathrm{O}-\mathrm{H}-----\mathrm{NH}_{2}$ hydrogen bonding. Many previous studies have demonstrated that in the vapour forms $\mathbf{1}$ and $\mathbf{2}$ are the lowest energy, molecular conformations of amino acids [19]. The relative energies of these two forms obtained at various theoretical levels are shown in Table 1. Calculations indicate that the relative energy of the two forms depends on the amino acid, on the basis set and on the correlation energy. Significant contributions come also from the ZPVE. At HF level $\mathbf{1}$ is more stable than 2 for all compounds by up to about $5 \mathrm{kcal} / \mathrm{mol}$. Electron correlation at both MP2 and DFT levels favours 2. This in many cases determines 2 to be more stable than $\mathbf{1}$. It is important to note that MP2 and DFT methods give the same order of stability, except for aspartic acid and, perhaps, for alanine. The effect of basis set was investigated at the 
correlated B97-1 level: the increase of the basis set size, by including diffuse functions, favours 1. The correlation energy effect seems to be more important than the basis set effect. Any way, difference in the relative energy is encompassed within $3 \mathrm{kcal} / \mathrm{mol}$, so in the gas the two forms probably coexist in all compounds. The ZPVE, evaluated at B97-1/cc-pVDZ level, favours 1 typically by $0.3-0.4 \mathrm{kcal} / \mathrm{mol}(0.9 \mathrm{kcal} / \mathrm{mol}$ in asparagine), but in no case it is able to change the order of stability of the two forms. Given the above results a strictly quantitative comparison with the previous theoretical estimates cannot be made. Accordingly in many cases our data differ significantly from literature data, recently reviewed by Dahereng and Dive [19]. The present work allows to compare geometries and relative energies of the two lowest-energy forms of amino acids on an homogeneous theoretical ground. Any way, to test our results, a quantitative comparison is made with literature data on glycine for which, owing to its small size, experimental and accurate theoretical data are available (Table 2). It is apparent that our theoretical geometrical parameters are in good agreement with experimental data and with the results of more sophisticated theoretical calculations such as CCSD/DZP ones [20]. The energy of $\mathbf{1}$ relative to $2(-0.84 \mathrm{kcal} / \mathrm{mol}$, when corrected for ZPVE) is somewhat overestimated with respect to the experimental value of $-1.4 \mathrm{kcal} / \mathrm{mol}$ [21] and to the CCSD value of $-1.43 \mathrm{kcal} / \mathrm{mol}$ [20]. Note that single point $\mathrm{CCSD}(\mathrm{T}) / \mathrm{DZP}$ calculations [20] gave $\mathrm{E}_{\mathrm{R}}=-1.06 \mathrm{kcal} / \mathrm{mol}$, while $\mathrm{MP} 2 / 6311++\mathrm{G}^{* *}$ calculations gave $\mathrm{E}_{\mathrm{R}}=-0.59$ [22-24] and -1.05 [25] kcal/mol vs. a DFT-B3LYP/6-311G** datum of $-0.82 \mathrm{kcal} / \mathrm{mol}$ [25].

\subsection{Dipole moments}

HF, MP2 and B97-1 gas-phase dipole moments, $\mu_{\mathrm{s}}$, of amino acids obtained with the augcc-pVDZ basis set are reported in Table 3. B97-1 and MP2 results are very close with each other. To validate the results, $\mu$ of glycine was calculated also at the higher CCSD(T) level, 
using the same basis set. The obtained $\mu$ values for both $\mathbf{1}$ and $\mathbf{2}$ forms fully support the accuracy of MP2 and B97-1 methods in describing the electronic distribution in the amino acids. Correlated $\mu$ values are lower than HF ones, especially for form 2. The amino acid polarity is, as expected, very dependent on the molecular conformation. This issue requires specific investigation and it is outside the aim of the present work, however data in Table 3 show that the simultaneous rotations around the $\mathrm{C}-\mathrm{C}, \mathrm{C}-\mathrm{O}$ and $\mathrm{C}-\mathrm{N}$ bonds in the amino-acidic framework, to pass from 1 to 2 , produce a remarkable increase of $\mu$, as exemplified in glycine (Fig. 1). Exceptions are glutamine and asparagine, where dipole orientation of the $-\mathrm{CH}_{2}-\mathrm{CH}_{2}-$ $\mathrm{CO}-\mathrm{NH}_{2}$ and $-\mathrm{CH}_{2}-\mathrm{CO}-\mathrm{NH}_{2}$ residues makes $\mu(2)<\mu(\mathbf{1})$. Experimental $\mu$ values of amino acids in the gas or in non-polar solvents are not known, but for glycine [26] and tryptophane [27]. Gas-phase dipole moments of glycine $\mathbf{1}$ and $\mathbf{2}$ conformers were obtained by microwave spectroscopy as 1.10 and $5.45 \mathrm{D}$, in excellent agreement with our MP2 and CCSD(T) previsions of 1.28 and 5.46 D, respectively. B97-1/aug-cc-PVDZ calculations produce a slight overestimation of ca. $0.1 \mathrm{D}$ relative to the $\operatorname{CCSD}(\mathrm{T})$ figures.

From deflection measurements of a molecular beam in inhomogeneous electric field the gasphase dipole moment of form 2 of tryptophane was inferred to be close to the calculated MP2/6-31G** value of 3.08-3.99 D [27]. Our MP2/aug-cc-PVDZ datum of $2.73 \mathrm{D}$ is in partial agreement, suggesting that a more accurate search of the chain conformation is needed.

\subsection{Electronic polarizabilities}

HF, MP2 and B97-1 electronic dipole polarizabilities carried out with the aug-cc-pVDZ basis set are shown in Table 4, together with available experimental values in water solution for a tentative comparison; dynamic values were obtained at the $578 \mathrm{~nm}$ laser wavelength 
used in the experimental measurements in water solution [9]. To compare static and dynamic values in calculating static dipole polarizabilities we omitted contributions coming from the permanent dipole moment orientation of the floppy molecule, since they are absent in the dynamic regime at $578 \mathrm{~nm}$. The results show:

a) MP2 and B97-1 data are very close with each other. The usually observed overestimation of the molecular polarizability by DFT methods is here not observed. The accuracy of the MP2 and B97-1 data has been successfully assessed, as for $\mu$, by $\operatorname{CCSD}(\mathrm{T})$ calculations on glycine (Table 4). HF/aug-cc-pVDZ values are very close to the HF/POL-Sadlej ones reported by Hansen et al. [11]. Our correlated values are somewhat smaller than those reported by Tulip and Clark on alanine, isoleucine, leucine and valine [12], while they well correlate with the DFT-LB94/QZ4p polarizabilities of the amino acid residues reported by Smart et al. [13]. We consider the reported values as the most accurate dipole polarizability data of the present amino acids to date.

b) Correlation energy produces a significant increase of $\left\langle\alpha^{e}>\right.$ of $6-10 \%$.

c) Dynamic values at $\lambda=578 \mathrm{~nm}$ are greater than the static ones by $3-4 \%$.

d) Quite important, $\left\langle\alpha^{\mathrm{e}}\right\rangle$ values of form $\mathbf{1}$ are almost equal to those of form 2, despite a marked difference in the charge distribution, as indicated by the relative $\mu$ values.

e) Quite unexpectedly gas-phase $<\alpha^{\mathrm{e}}>$ values are very close to the experimental values in water solution, where the amino acids are notoriously in a zwitterionic form. The following relations have been found:

$<\alpha>_{\text {B97-1/aug-cc-pvdz }}=-2.61+1.02<\alpha>_{\exp }, \quad \mathrm{r}^{2}=0.992$ 


$$
<\alpha^{\mathrm{e}}>_{\text {MP2/aug-cc-pvdz }}=-2.72+1.01<\alpha>_{\text {exp }}, \quad r^{2}=0.992
$$

Dynamic data correlate similarly:

$$
<\alpha^{\mathrm{e}}>_{\text {B97-1/aug-cc-pvdz }}=-4.94+1.08<\alpha>_{\exp }, \quad \mathrm{r}^{2}=0.990
$$

Slopes are near to unit in all cases. These results induced us to carry out gas-phase dipole polarizability calculations on the zwitterionic structure, $\left\langle\alpha^{\mathrm{e}}\right\rangle_{\mathrm{zw}}$ of the amino acids, which was obtained by geometry optimization procedures in water solution at B97-1/cc-pVDZ level by the Polarizable Continuum Method (PCM) [28]. The results are reported in Table 4. It can be seen that $\left\langle\alpha^{\mathrm{e}}\right\rangle_{\mathrm{zw}}$ are very close to $\left\langle\alpha^{\mathrm{e}}\right\rangle$ of the neutral forms, being only $2-8 \%$ higher. Also $\left\langle\alpha^{\mathrm{e}}\right\rangle_{\mathrm{zw}}$ can be linearly related to $\langle\alpha\rangle_{\exp }$ (Fig. 2) following the relation

$$
<\alpha^{\mathrm{e}}>_{\text {B97-1/aug-cc-pvdz }}=-0.75+1.04<\alpha>\exp , \mathrm{r}^{2}=0.993
$$

The above behaviour suggests that the molecular polarization of the amino acid is not strictly dependent on the molecular structure and conformation, but it is rather governed by some other physical properties such as molecular volume (V), total number of electrons $(\mathrm{Z})$ and atomic polarizabilty sum $\left(\sum_{\mathrm{i}}<\alpha^{\mathrm{e}}>_{\mathrm{i}}\right)$. Relations between $<\alpha^{\mathrm{e}}>$ and these properties are reported in Figs. 3-5. The dependence is indeed linear with a good statistics. It is of interest to note that the $<\alpha^{\mathrm{e}}>/ Z$ correlation puts in evidence that amino acids constitute a family of very polarizable molecules having a $<\alpha^{\mathrm{e}}>/ Z$ ratio of $0.24 \AA^{3}$, comparable to that exhibited by non substituted hydrocarbons (saturated, unsaturated, aromatic, etc.) which show a $<\alpha^{\mathrm{e}}>/ Z$ ratio of $0.25 \AA^{3}$, what makes to classify them as the most polarizable molecules [4]. The $<\alpha^{\mathrm{e}}>/ \Sigma_{\mathrm{i}}<\alpha^{\mathrm{e}}>_{\mathrm{i}}$ correlation has a slope $(0.75)$ much smaller than unit. This suggests that a simple additive approach to the molecular polarizability of the amino acids can hardly be applicable. Indeed such a value indicates a considerable loss of polarizability, i.e. an increase 
of the molecular stability, in the molecule relative to the sum of the atomic contributions, along the series as $Z$ increases. Accordingly a linear inverse correlation can be drawn between $\left\langle\alpha^{\mathrm{e}}\right\rangle$ and the chemical hardness $\eta$ (Fig. 6), this property having been obtained from data in Table 5, as [29]

$$
\eta=\frac{\varepsilon_{\mathrm{L}}-\varepsilon_{\mathrm{H}}}{2}+\varepsilon_{\mathrm{H}}+\mathrm{IP}
$$

where $\varepsilon_{\mathrm{L}}$ and $\varepsilon_{\mathrm{H}}$ are the energies of the lowest unoccupied, LUMO, and the highest occupied molecular orbitals, HOMO, respectively, and IP is the vertical $\triangle \mathrm{SCF}$ ionization potential.

\subsection{Vibrational polarizabilities}

Total averaged vibrational polarizability, $\left\langle\alpha^{\mathrm{v}}\right\rangle$, and the main contributions from the individual vibrational modes of the amino acid $\mathbf{1}$ and $\mathbf{2}$ forms are reported in Table 6 . In calculating $\left\langle\alpha^{\mathrm{v}}>\right.$ we omitted contributions coming from vibrational modes with frequency lower than $200 \mathrm{~cm}^{-1}$ which would give exceptionally high unrealistic $\left\langle\alpha^{\mathrm{v}}\right\rangle$ values. Indeed low-frequency modes are likely improperly described by the Bishop-Kirtman perturbation treatment $[16,30]$. The results show that $\left\langle\alpha^{\mathrm{v}}\right\rangle$ is an important part of the total polarizability showing values ranging from ca. 10 a.u. in proline to ca. 45 a.u. in asparagine and glutamine. Averaged vibrational polarizability of form $\mathbf{1}$ is greater than that of form $\mathbf{2}$ principally owing to rocking and wagging contributions of the $\mathrm{NH}_{2}$ group. It follows that $\left.\left\langle\alpha^{\mathrm{v}}\right\rangle /\left\langle\alpha^{\mathrm{e}}\right\rangle(\mathbf{1})\right\rangle$ $<\alpha^{\mathrm{v}}>/<\alpha^{\mathrm{e}}>(2)$. According to equation (1), the most important vibrational contributions come from low-frequency angular deformation modes. Stretching modes, despite having higher intensity, do not significantly contribute. It is of interest to note that the $\delta(\mathrm{OH})$ contribution to 
$\left.<\alpha^{\mathrm{v}}\right\rangle$ is negligible in form $\mathbf{1}$ of all compounds, whilst it is significant in form $\mathbf{2}$ because this mode produces a $\partial \mu_{\mathrm{i}}^{\mathrm{e}} / \partial \mathrm{Q}_{\mathrm{a}}$ in $\mathbf{2}$ greater than in $\mathbf{1}$.

\section{Summary and conclusions}

We have calculated molecular dipole moments, $\mu$, and polarizabilities, $\alpha$, of two lowestenergy conformations of the twenty naturally occurring amino acids, using conventional ab initio and Density Functional Theory methods. The aim of the work was to investigate the effect on $\mu$ and $\alpha$ of the amino-acidic $\mathrm{NH}_{2}-\mathrm{CH}-\mathrm{COOH}$ backbone conformation in the $\mathbf{1}$ and 2 forms, which bring $\mathrm{NH}-\mathrm{O}$ and $\mathrm{OH}-\mathrm{N}$ type hydrogen bonds, respectively. The reliability of the reported data has been validated by performing $\operatorname{CCSD}(\mathrm{T}) /$ aug-cc-pVDZ calculations of $\mu$ and $\alpha$ of the smallest amino acid glycine.

One has found that on passing from 1 to 2 intensity and direction of the dipole vector change noticeably, suggesting that $\mu$ might be a precious property in studying molecular conformation of amino acids.

Gas-phase dipole polarizabilities of the neutral 1 and $\mathbf{2}$ forms are in good agreement with each other and linearly correlate with the experimental data in water solutions where the amino acids are known to exist in a zwitterionic form. This is a rather unexpected result. However, gas-phase polarizabilities of zwitterionic structures, as obtained by geometry optimization in water, are also close to the polarizability values of the neutral forms. These results suggest that $\alpha$-amino acid polarizabilities are not much dependent on molecular structure and conformations although the dependence of $\left\langle\alpha^{\mathrm{e}}\right\rangle$ on the atomic polarizability sum suggests that a simple additive model to the molecular polarizability of amino acids can hardly be 
supported. On the other hand $\left\langle\alpha^{\mathrm{e}}>\right.$ linearly correlates with the molecular volume, molecular hardness and total electron number. The latter correlation makes to classify $\alpha$-amino acids as one of the most polarizable family of compounds.

Vibrational polarizability is an important fraction of the total polarizability. The most important contributions come from low-frequency angular deformation modes.

\section{Acknowledgments}

Work partially supported by MIUR, Rome

\section{References}

[1] D.A. McQuarrie, Statistical Mechanics (Harper \& Row Publishers, New York, 1973).

[2] C.J.F. Bottcher, Theory of Electric Polarization (Elsevier, Amsterdam, 1952).

[3] C. Castiglioni, M. Gussoni, M. Del Zoppo, and G. Zerbi, Relaxation contribution to hyperpolarizability. A semiclassical model, Solid State Comm. 82 (1992) 13-17.

[4] M. Gussoni, M. Rui and G. Zerbi, Electronic and relaxation contribution to linear molecular polarizability. An analysis of the experimental values, J. Mol. Struct. 447 (1998) 163-215. 
[5] D. Voges and A. Karshikoff, A model of a local dielectric constant in proteins,

J. Chem. Phys. 108 (1998) 2219-2227.

[6] X. Song, An inhomogeneous model of protein dielectric properties: Intrinsic polarizabilities of amino acids, J. Chem. Phys. 116 (2002) 9359-9363

[7] G.A. Kaminski, H.A. Stern, B.J. Berne, R.A. Friesner, Y.X. Cao, R.B. Murphy, R. Zhou and T.A. Halgren, Development of a polarizable force field for proteins via Ab Initio quantum chemistry: First generation model and gas phase tests, J. Comput. Chem. 23 (2002) 1515-1531.

[8] R.P. Verma, A. Kurup and C. Hansch, On the role of polarizability in QSAR., Bioorg. Med. Chem. 13 (2005) 237-255.

[9] G. Khanarian and W.J. Moore, The Kerr effect of amino acids in water, Austr.

J. Chem. 33 (1980) 1727-1741.

[10] T.L. McMeekin, M. Wilensky and M.L. Groves, Refractive indices of proteins in relation to amino acid composition and specific volume, Biochem. Biophys. Res. Commun. 7 (1962) 151-156.

[11] T. Hansen, L. Jensen, P.-O. Astrand and K. Mikkelsen, Frequency-Dependent Polarizabilities of Amino Acids as Calculated by an Electrostatic Interaction Model, J. Chem. Theory Comput. 1 (2005) 626-633. 
[12] P.R. Tulip and S.J. Clark, Dielectric and vibrational properties of amino acids,

J. Chem. Phys. 121 (2004) 5201-5210.

[13] M. Swart, J.G. Snijders and P.Th. van Duijnen, Polarizabilities of amino acid residues, J. Comp. Meth. Sci. Engin., 4 (2004) 419-425.

[14] F.A. Hamprecht, A.J. Cohen, D.J. Tozer and N.C. Handy, Development and assessment of new exchange-correlation functionals, J. Chem. Phys. 109 (1998) 6264-6271.

[15] H.A. Kurtz, J.J.P. Stewart and K.M. Dieter, Calculation of the nonlinear optical properties of molecules, J. Comput. Chem. 11 (1990) 82-87.

[16] D.M. Bishop, Molecular vibration and nonlinear optics, Adv. Chem. Phys. 104 (1998) 1-40.

[17] M.J. Frisch, G.W. Trucks, H.B. Schlegel, G.E. Scuseria, M.A. Robb, J.R.

Cheeseman, V.G. Zakrzewski, J.A. Montgomery Jr., R.E. Stratmann, J.C. Burant, S.

Dapprich, J.M. Millam, A.D. Daniels, K.N. Kudin, M.C. Strain, O. Farkas, J.

Tomasi, V. Barone, M. Cossi, R. Cammi, B. Mennucci, C. Pomelli, C. Adamo, S.

Clifford, J. Ochterski, G.A. Petersson, P.Y. Ayala, Q. Cui, K. Morokuma, D.K.

Malick, A.D. Rabuck, K. Raghavachari, J. Cioslowski, J.V. Ortiz, A.G. Baboul, B.B. Stefanov, G. Liu, A. Liashenko, P. Piskorz, I. Komoromi, R. Gomperts, R.L. 
Martin, D.J. Fox, T. Keith, M. A. Al-Laham, C.Y. Peng, A. Nanayakkara, C.

Gonzalez, M. Challacombe, P.M.W. Gill, B. Johnson, W. Chen, M.W. Wong, J.L.

Andres, M. Head-Gordon, E.S. Replogle, J.A. Pople, GAUSSIAN-03, Rev. B.03

Gaussian Inc., Pittsburgh, PA, 2003.

[18] M.W. Schmidt, K.K. Baldridge, J.A. Boatz, S.T. Elbert, M.S. Gordon, J.H. Jensen, S. Koseki, N. Matsunaga, K.A. Nguyen, S. Su, T.L. Windus, M. Dupuis and J.A. Montgomery Jr., General atomic and molecular electronic structure system, J. Comput. Chem. 14 (1993) 1347-1363.

[19] D. Dehareng and G. Dive, Vertical Ionization Energies of $\alpha$-L-Amino Acids as a Function of their Conformation: an Ab Initio Study, Int. J. Mol. Sci., 5 (2004) 301-332.

[20] C.H. Hu, M. Shen and H.F. Schaefer III, Glycine conformational analysis, J. Am. Chem. Soc., 115 (1993) 2923-2929.

[21] R.D. Suenram and F.J. Lovas, Millimeter wave spectrum of glycine. A new conformer, J. Am. Chem. Soc., 102 (1980) 7180-7184.

[22] A.G. Csaszar, Conformers of gaseous glycine, J. Am. Chem. Soc. 114 (1992) $9568-9575$.

[23] L.F. Pacios, O. Galvez and P.C. Gomez, Intramolecular Effects and Relative Stabilities of Conformers of Gaseous Glycine, J. Phys. Chem. A 105 (2001) 5232-5241.

[24] T.F. Miller III and D.C. Clary, Quantum free energies of the conformers of glycine on an 
ab initio potential energy surface, Phys. Chem. Chem. Phys. 6 (2004) 2563-2571.

[25] B. Herrera, O. Dolgounitcheva, V.G. Zakrzewski, A. Toro-Labbe and J.V. Ortiz, Conformational Effects on Glycine Ionization Energies and Dyson Orbitals, J. Phys.

Chem. A 108 (2004) 11703-11708.

[26] F.J. Lovas, Y. Kawashima, J.-U. Grabow, R.D. Suenram, G.T. Fraser, E. Hirota, Microwave Spectra, Hyperfine Structure, and Electric Dipole Moments for Conformers I and II of Glycine, Astrophys. J., 455 (1995) L201-L204.

[27] R. Antoine, I. Compagnon, D. Rayane, M. Broyer, Ph. Dugourd, G. Breaux, F.C. Hagemeister, D. Pippen, R.R. Hudgins, M.F. Jarrold, Eletric dipole moments and conformations of isolated peptides, Eur. Phys. J. D, 20 (2002) 583-587.

[28] M.Cossi, N. Rega, G. Scalmani, V.Barone, Energies, structures, and electronic properties of molecules in solution with the C-PCM solvation model J. Comput. Chem., 24 (2003) $669-681$.

[29] D.J. Tozer and F. De Proft, Computation of the Hardness and the Problem of Negative Electron Affinities in Density Functional Theory, J. Phys. Chem. A, 109 (2005) 8923-8929.

[30] U. Ekart and A.J. Sadlej, Vibrational corrections to electric properties of weakly bound systems, Mol. Phys., 99 (2001) 735-743. 
Table 1

Relative energy (kcal/mol) of form 2 vs. 1 of amino acids calculated on the B97-1/cc-pVDZ geometry.

\begin{tabular}{|c|c|c|c|c|c|c|}
\hline & & $\begin{array}{l}\mathrm{HF} / \\
\text { aug-cc-pVDZ }\end{array}$ & $\begin{array}{l}\text { MP2/ } \\
\text { aug-cc-pVDZ }\end{array}$ & $\begin{array}{l}\text { B97-1/ } \\
\text { aug-cc-pVDZ }\end{array}$ & $\begin{array}{l}\text { B97-1/ } \\
\text { cc-pVDZ }\end{array}$ & $\begin{array}{l}\text { B97-1/ } \\
\text { cc-pVDZ }+\Delta Z \text { ZVE }\end{array}$ \\
\hline & & & & & 0 & \\
\hline 1 & Ala & 2.95 & 0.34 & -0.04 & -0.74 & $\begin{array}{l}-0.38 \\
\end{array}$ \\
\hline 2 & Arg & 4.41 & 1.40 & 0.96 & 0.92 & 0.93 \\
\hline 3 & Asn & 1.55 & -2.42 & -3.13 & -4.13 & -3.23 \\
\hline 4 & Asp & 4.95 & 0.37 & -1.18 & -2.42 & -2.00 \\
\hline 5 & Cys & 3.49 & 1.28 & 0.88 & -0.01 & 0.43 \\
\hline 6 & Gln & 0.71 & -1.94 & -2.09 & -2.10 & -1.78 \\
\hline 7 & Glu & 0.79 & -0.95 & -1.73 & -2.80 & -2.59 \\
\hline 8 & Gly & 3.46 & 0.54 & 0.46 & 0.46 & 0.75 \\
\hline 9 & His & 5.46 & 3.14 & 2.68 & 1.63 & 1.79 \\
\hline 10 & Ile & 2.20 & -0.49 & -0.53 & -0.94 & -0.82 \\
\hline 11 & Leu & 2.56 & -0.32 & -0.42 & -0.87 & -0.42 \\
\hline 12 & Lys & 2.64 & -0.16 & -0.28 & -0.60 & -0.21 \\
\hline 13 & Met & 2.07 & -0.66 & -0.75 & -0.86 & -0.62 \\
\hline 14 & Phe & 4.64 & 2.03 & 1.61 & 1.05 & 1.23 \\
\hline 15 & Pro & 2.22 & -1.40 & -1.22 & -1.66 & -1.27 \\
\hline 16 & Ser & 0.19 & -2.84 & -3.72 & -6.51 & -5.7 \\
\hline 17 & Thr & 1.72 & -0.88 & -1.47 & -1.90 & -1.56 \\
\hline 18 & Trp & 4.86 & 1.91 & 1.36 & 0.33 & 0.53 \\
\hline 19 & Tyr & 4.68 & 2.12 & 1.68 & 1.07 & 1.27 \\
\hline 20 & Val & 2.26 & -0.48 & -0.48 & -0.89 & -0.57 \\
\hline
\end{tabular}


Table 2

Geometries and relative energies of glycine forms. ${ }^{\text {a }}$

\begin{tabular}{|c|c|c|c|c|c|}
\hline & \multicolumn{2}{|l|}{ Form 1} & \multicolumn{2}{|l|}{ Form 2} & \multirow{2}{*}{ Exp. ${ }^{d}$} \\
\hline & $\begin{array}{l}\text { B97-1/ } \\
\text { cc-pVDZ b }\end{array}$ & $\begin{array}{l}\text { CCSD/ } \\
\mathrm{DZP}^{\mathrm{c}}\end{array}$ & $\begin{array}{l}\text { B97-1/ } \\
\text { cc-pVDZ b }\end{array}$ & $\begin{array}{l}\mathrm{CCSD} / \\
\mathrm{DZP}^{\mathrm{c}}\end{array}$ & \\
\hline $\mathrm{r}(\mathrm{O}-\mathrm{H})$ & 0.944 & 0.972 & 0.989 & 0.982 & 0.966 \\
\hline $\mathrm{r}(\mathrm{C}-\mathrm{O})$ & 1.353 & 1.359 & 1.341 & 1.347 & 1.354 \\
\hline $\mathrm{r}(\mathrm{C}=\mathrm{O})$ & 1.211 & 1.216 & 1.206 & 1.214 & 1.204 \\
\hline $\mathrm{r}(\mathrm{C}-\mathrm{C})$ & 1.526 & 1.525 & 1.541 & 1.533 & 1.529 \\
\hline $\mathrm{r}(\mathrm{C}-\mathrm{H})$ & 1.105 & 1.098 & & & 1.081 \\
\hline $\mathrm{r}(\mathrm{C}-\mathrm{N})$ & 1.452 & 1.458 & 1.471 & 1.475 & 1.466 \\
\hline $\mathrm{r}(\mathrm{N}-\mathrm{H})$ & 1.024 & 1.021 & 1.021 & 1.018 & 1.001 \\
\hline$\theta(\mathrm{H}-\mathrm{O}-\mathrm{C})$ & 105.9 & 105.9 & 103.9 & 104.4 & (112.3) \\
\hline$\theta(\mathrm{O}=\mathrm{C}-\mathrm{C})$ & 125.0 & 125.7 & 123.1 & 122.3 & 125.1 \\
\hline$\theta(\mathrm{O}-\mathrm{C}-\mathrm{C})$ & 111.9 & 111.5 & 113.1 & 114.1 & 111.6 \\
\hline$\theta(\mathrm{C}-\mathrm{C}-\mathrm{N})$ & 115.1 & 115.4 & 110.5 & 111.2 & 112.1 \\
\hline$\theta(\mathrm{H}-\mathrm{N}-\mathrm{C})$ & 108.2 & 108.8 & 110.6 & 111.0 & (113.2) \\
\hline$\theta(\mathrm{H}-\mathrm{N}-\mathrm{H})$ & 103.5 & 104.7 & 106.1 & 106.9 & (110.3) \\
\hline$\Sigma \theta^{\mathrm{e}}$ & 319.9 & 322.3 & 328.2 & 328.9 & 333.9 \\
\hline$E_{R}$ & $0.00(0.00)^{f}$ & 0.00 & $0.54(0.84)^{f}$ & 1.43 & $1.4 \pm 0.4$ \\
\hline
\end{tabular}

${ }^{\mathrm{a}}$ Bond lengths in $\AA$, bond angles in degrees, relative energies in $\mathrm{kcal} / \mathrm{mol}$.

${ }^{\mathrm{b}}$ Present work.

${ }^{c}$ Ref. [20]

${ }^{\mathrm{d}}$ Ref. [21]

${ }^{\text {e }} \Sigma \theta=2 \theta(\mathrm{H}-\mathrm{N}-\mathrm{C})+\theta(\mathrm{H}-\mathrm{N}-\mathrm{H})$

${ }^{\mathrm{f}}$ Value corrected for the zero-point vibrational energy. 
Table 3

Dipole moments (Debye) of amino acids. ${ }^{\text {a }}$

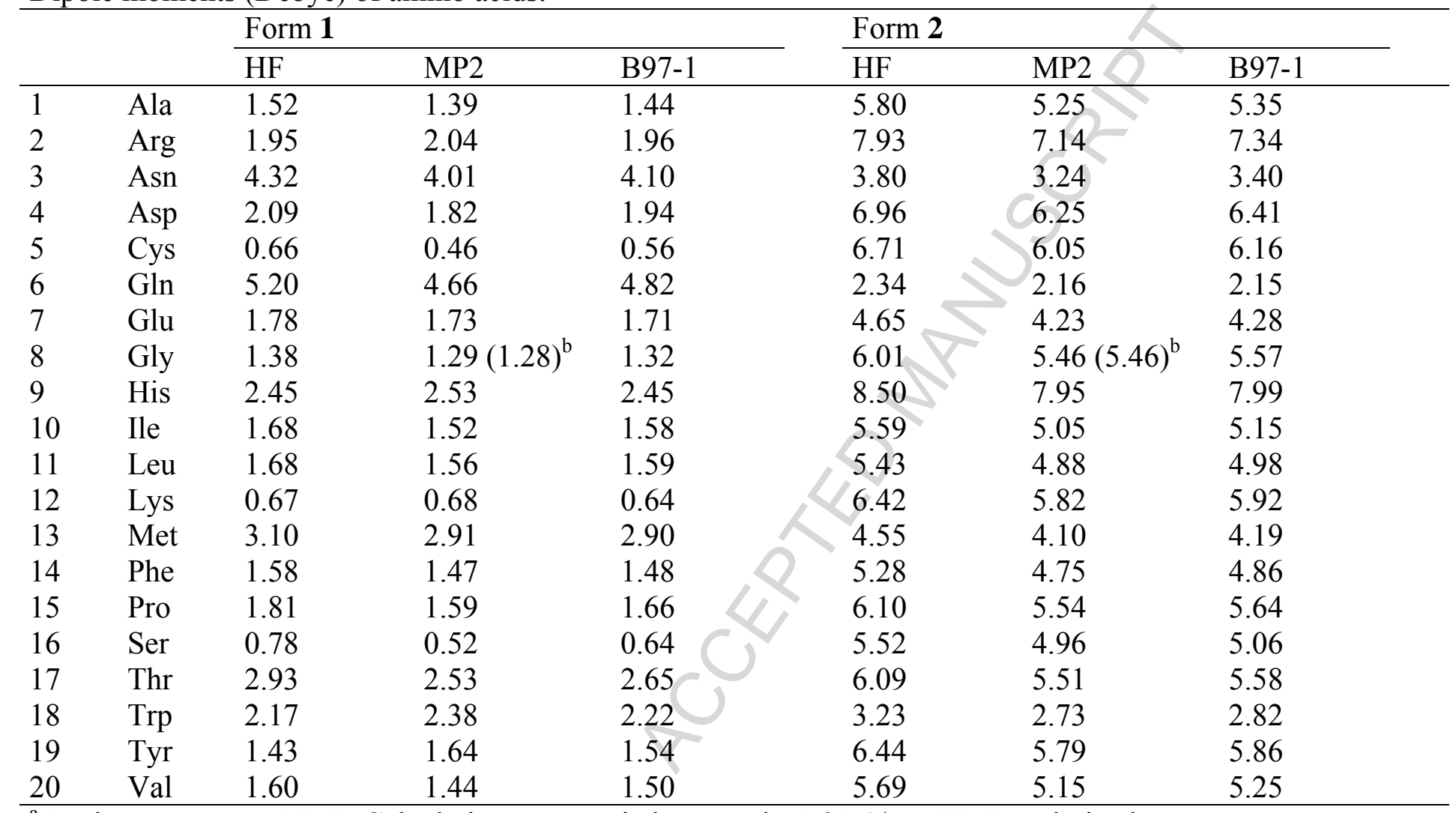

a Basis set: aug-cc-pVDZ. Calculations are carried out on the B97-1/cc-pVDZ optimized geometry.

${ }^{\mathrm{b}}$ From $\operatorname{CCSD}(\mathrm{T}) / \mathrm{aug}-\mathrm{cc}-\mathrm{pVDZ}$ calculations. 
Table 4

Mean dipole polarizability (a.u.) of amino acids. Dynamic values at $\omega=0.0788$ a.u. ${ }^{\text {a }}$

\begin{tabular}{|c|c|c|c|c|c|c|c|c|c|c|c|}
\hline & & \multicolumn{4}{|l|}{ Form 1} & \multicolumn{4}{|l|}{ Form 2} & \multirow{3}{*}{$\begin{array}{l}\text { ZW-gas } \\
\text { B97-1 } \\
<\alpha^{\mathrm{e}}>(0 ; 0)\end{array}$} & \multirow{3}{*}{ Exp. ${ }^{b}$} \\
\hline & & \multirow{2}{*}{$\begin{array}{l}\mathrm{HF} \\
<\alpha^{\mathrm{e}}>(0 ; 0)\end{array}$} & \multirow{2}{*}{$\begin{array}{l}\text { MP2 } \\
<\alpha^{\mathrm{e}}>(0 ; 0)\end{array}$} & \multicolumn{2}{|l|}{ B97-1 } & \multirow{2}{*}{$\begin{array}{l}\mathrm{HF} \\
<\alpha^{\mathrm{e}}>(0 ; 0)\end{array}$} & \multirow{2}{*}{$\begin{array}{l}\text { MP2 } \\
<\alpha^{\mathrm{e}}>(0 ; 0)\end{array}$} & \multicolumn{2}{|l|}{ B97-1 } & & \\
\hline & & & & $\left\langle\alpha^{\mathrm{e}}>(0 ; 0)\right.$ & $\left\langle\alpha^{\mathrm{e}}\right\rangle(-\omega ; \omega)$ & & & $\left\langle\alpha^{\mathrm{e}}\right\rangle(0 ; 0)$ & $\left\langle\alpha^{\mathrm{e}}\right\rangle(-\omega ; \omega)$ & & \\
\hline 1 & Ala & 50.68 & 55.26 & 55.98 & 57.44 & 50.46 & 54.99 & 55.41 & 56.77 & 58.09 & 55.88 \\
\hline 2 & Arg & 109.85 & 120.16 & 121.71 & 125.59 & 109.63 & 120.20 & 121.38 & 125.23 & 124.58 & 115.62 \\
\hline 3 & Asn & 70.59 & 78.33 & 78.98 & 81.24 & 70.52 & 78.21 & 78.42 & 80.59 & 82.05 & 79.82 \\
\hline 4 & Asp & 65.90 & 72.71 & 73.43 & 75.33 & 65.87 & 72.91 & 73.19 & 75.02 & 76.92 & 79.72 \\
\hline 5 & Cys & 70.42 & 75.80 & 76.76 & 79.10 & 70.51 & 76.18 & 77.03 & 79.43 & 80.34 & \\
\hline 6 & Gln & 82.40 & 90.80 & 91.85 & 94.44 & 81.86 & 90.26 & 90.93 & 93.40 & 94.19 & \\
\hline 7 & Glu & 77.87 & 85.51 & 86.66 & 88.95 & 77.29 & 85.05 & 85.90 & 88.06 & 89.48 & 90.45 \\
\hline 8 & Gly & 39.15 & $43.09(42.98)^{\mathrm{c}}$ & 43.57 & 44.70 & 39.22 & $43.18(43.06)^{\mathrm{c}}$ & 43.40 & 44.50 & 47.13 & 44.26 \\
\hline 9 & His & 94.22 & 101.01 & 102.40 & 105.93 & 94.13 & 100.79 & 101.89 & 105.27 & 105.87 & 102.64 \\
\hline 10 & Ile & 84.77 & 91.24 & 92.67 & 95.04 & 84.31 & 90.67 & 91.84 & 94.09 & 94.88 & 95.28 \\
\hline 11 & Leu & 85.39 & 91.98 & 93.47 & 95.90 & 84.97 & 91.55 & 92.78 & 95.11 & 96.00 & 94.51 \\
\hline 12 & Lys & 94.53 & 102.37 & 104.18 & 107.04 & 94.18 & 102.01 & 103.56 & 106.34 & 106.96 & \\
\hline 13 & Met & 95.53 & 102.22 & 103.81 & 106.99 & 95.09 & 101.78 & 103.11 & 106.19 & 106.56 & 102.18 \\
\hline 14 & Phe & 115.97 & 122.39 & 123.64 & 128.57 & 116.19 & 122.64 & 123.73 & 128.64 & 127.82 & 122.96 \\
\hline 15 & Pro & 68.60 & 74.18 & 75.19 & 77.13 & 68.14 & 73.61 & 74.23 & 76.02 & 76.82 & 73.51 \\
\hline 16 & Ser & 54.36 & 59.90 & 60.69 & 62.27 & 53.91 & 59.42 & 59.93 & 61.42 & 63.86 & 61.24 \\
\hline 17 & Thr & 65.57 & 71.56 & 72.56 & 74.37 & 65.26 & 71.36 & 72.07 & 73.82 & 75.47 & 73.73 \\
\hline 18 & Trp & 147.07 & 155.77 & 157.49 & 165.42 & 147.01 & 156.26 & 157.56 & 165.46 & 161.72 & 157.81 \\
\hline 19 & Tyr & 120.00 & 128.26 & 129.76 & 135.17 & 120.36 & 128.68 & 130.04 & 135.49 & 134.43 & \\
\hline 20 & Val & 73.16 & 79.03 & 80.19 & 82.26 & 72.75 & 78.5 & 79.39 & 81.34 & 82.31 & 81.51 \\
\hline
\end{tabular}

a Basis set: aug-cc-pVDZ. Calculations are carried out on the B97-1/cc-pVDZ optimized geometry.

${ }^{\mathrm{b}}$ Water solution, Ref. [9].

${ }^{\mathrm{c}}$ From CCSD(T)/aug-cc-pVDZ calculations. 
Table 5

Ionization potential, IP $(\mathrm{eV})$, molecular hardness, $\eta(\mathrm{eV})$, LUMO-HOMO energy

difference, $\varepsilon_{\mathrm{L}}-\varepsilon_{\mathrm{H}}(\mathrm{eV})$ of amino acids. B97-1/cc-pVDZ results.

\begin{tabular}{|c|c|c|c|c|c|c|c|}
\hline & & \multicolumn{3}{|c|}{ Form 1} & \multicolumn{3}{|c|}{ Form 2} \\
\hline & & IP & $\eta$ & $\varepsilon_{L}-\varepsilon_{H}$ & IP & $\eta$ & $\varepsilon_{\mathrm{L}}-\varepsilon_{\mathrm{H}}$ \\
\hline 1 & Ala & 9.38 & 6.13 & 7.08 & 9.38 & 6.15 & 7.26 \\
\hline 2 & Arg & 8.04 & 5.10 & 6.16 & 7.80 & 5.16 & 6.06 \\
\hline 3 & Asn & 8.96 & 5.61 & 7.02 & 8.83 & 5.50 & 6.44 \\
\hline 4 & Asp & 9.30 & 5.75 & 6.98 & 9.36 & 5.58 & 6.48 \\
\hline 5 & Cys & 8.82 & 5.62 & 6.52 & 8.76 & 5.58 & 6.52 \\
\hline 6 & Gln & 8.72 & 5.44 & 6.96 & 8.75 & 5.60 & 7.30 \\
\hline 7 & Glu & 9.09 & 5.60 & 6.96 & 9.11 & 5.70 & 7.24 \\
\hline 8 & Gly & 9.56 & 6.31 & 7.18 & 9.56 & 6.40 & 7.44 \\
\hline 9 & His & 8.11 & 5.15 & 6.06 & 8.19 & 5.33 & 6.28 \\
\hline 10 & Ile & 9.10 & 5.84 & 6.96 & 9.18 & 6.06 & 7.38 \\
\hline 11 & Leu & 9.20 & 5.94 & 7.00 & 9.23 & 6.08 & 7.40 \\
\hline 12 & Lys & 8.34 & 5.27 & 6.56 & 8.40 & 5.49 & 6.88 \\
\hline 13 & Met & 8.19 & 5.27 & 6.02 & 8.27 & 5.49 & 6.36 \\
\hline 14 & Phe & 8.39 & 4.98 & 6.44 & 8.36 & 4.96 & 6.38 \\
\hline 15 & Pro & 8.59 & 5.65 & 6.44 & 9.10 & 5.91 & 7.16 \\
\hline 16 & Ser & 9.24 & 6.00 & 7.08 & 9.33 & 5.84 & 7.06 \\
\hline 17 & Thr & 9.11 & 5.99 & 7.06 & 9.15 & 6.03 & 7.26 \\
\hline 18 & $\operatorname{Trp}$ & 7.24 & 4.35 & 5.20 & 7.25 & 4.36 & 5.18 \\
\hline 19 & Tyr & 7.84 & 4.75 & 5.74 & 7.80 & 4.76 & 5.80 \\
\hline 20 & Val & 9.17 & 5.90 & 6.98 & 9.22 & 6.10 & 7.38 \\
\hline
\end{tabular}


Table 6

Main contributions to vibrational polarizabilities (a.u.) of $\mathbf{1}$ and $\mathbf{2}$ forms of amino acids. Form 1

\begin{tabular}{lllll}
\hline$\omega$ & $\mathrm{I}_{\mathrm{IR}}$ & mode $^{\mathrm{a}}$ & $\left.<\alpha^{\mathrm{v}}\right\rangle$ & $<\alpha^{\mathrm{v}}>/<\alpha^{\mathrm{e}}>$ \\
$\left(\mathrm{cm}^{-1}\right)$ & $(\mathrm{km} / \mathrm{mol})$ & & \\
\hline
\end{tabular}

Form 2

$\omega$

$\left.\mathrm{I}_{\mathrm{IR}}(\mathrm{km} / \mathrm{mol}) \quad \operatorname{mode}^{\mathrm{a}} \quad<\alpha^{\mathrm{v}}\right\rangle \quad\left\langle\alpha^{\mathrm{v}}>/<\alpha^{\mathrm{e}}\right\rangle$

$\left(\mathrm{cm}^{-1}\right) \quad(\mathrm{km} / \mathrm{mol})$

$1 \quad$ Ala

$\begin{array}{llll}218 & 37 & \rho \mathrm{NH}_{2} & 7.08 \\ 599 & 64 & \tau \mathrm{OH} & 1.6 \\ 1151 & 211 & \delta \mathrm{OH} & 1.4 \\ & & \text { Total } & 17.74\end{array}$

$\left(\mathrm{cm}^{-1}\right)$

\begin{tabular}{lllll}
$\left(\mathrm{cm}^{-1}\right)$ & & & & \\
\hline & & & & \\
1450 & 371 & $\delta \mathrm{OH}$ & 1.58 & \\
276 & 13 & $\rho \mathrm{CH}_{3}$ & 1.56 & \\
307 & 14 & $\rho \mathrm{NH}_{2}$ & 1.35 & \\
& & Total & 10.50 & 0.19
\end{tabular}

$2 \quad$ Arg 617

$\begin{array}{ll}617 & 127 \\ 237 & 18 \\ 776 & 159\end{array}$

$\begin{array}{lll}\omega \mathrm{NH}_{2} & 2.99 & \\ \rho \mathrm{NH}_{2} & 2.91 & \\ \gamma \mathrm{NH} & 2.37 & \\ \text { Total } & 29.98 & 0.25 \\ & & \\ \omega \mathrm{NH}_{2} & 21.91 & \\ \rho \mathrm{NH}_{2} & 5.71 & \\ \tau \mathrm{OH} & 1.44 & \\ \text { Total } & 42.33 & 0.53\end{array}$

324
294
514

41
28
80

$\begin{array}{ll}\rho \mathrm{NH}_{2} & 3.5 \\ \rho \mathrm{NH}_{2} & 2.86 \\ \gamma \mathrm{NH} & 2.72 \\ \text { Total } & 29.19\end{array}$

$\begin{array}{llll}3 & \text { Asn } & 277 & 187 \\ & 229 & 34\end{array}$

$\begin{array}{ll}229 & 34 \\ 635 & 65\end{array}$

$4 \quad$ Asp $\quad 220 \quad 33$

$\begin{array}{ll}615 & 121 \\ 932 & 109\end{array}$

$\begin{array}{lll}5 \quad \text { Cys } & 252 & 32 \\ & 618 & 83 \\ & 289 & 13\end{array}$

$\begin{array}{ll}\rho \mathrm{NH}_{2} & 6.20 \\ \tau \mathrm{OH} & 2.87 \\ \omega \mathrm{NH}_{2} & 1.13 \\ \text { Total } & 22.80 \\ & \\ \rho \mathrm{NH}_{2} & 4.48 \\ \tau \mathrm{OH} & 1.95 \\ \rho \mathrm{NH}_{2} & 1.36 \\ \text { Total } & 16.09\end{array}$

0.31

427
208
1465


225
257
892


216
281
365

169
13
466

$\begin{array}{ll}\omega \mathrm{NH}_{2} & 8.32 \\ v \mathrm{NH}--\mathrm{O} & 2.69 \\ \delta \mathrm{OH} & 1.95 \\ \text { Total } & 25.76\end{array}$

$v$ NH--O 2.57

$\begin{array}{lll}15 & v \mathrm{NH}--\mathrm{O} & 1.97 \\ 144 & \tau \mathrm{OH} & 1.63 \\ & \text { Total } & 18.82\end{array}$

$\begin{array}{lll}15 & v \mathrm{NH}--\mathrm{O} & 1.97 \\ 144 & \tau \mathrm{OH} & 1.63 \\ & \text { Total } & 18.82\end{array}$

$\begin{array}{lll}15 & v \mathrm{NH}--\mathrm{O} & 1.97 \\ 144 & \tau \mathrm{OH} & 1.63 \\ & \text { Total } & 18.82\end{array}$

0.26

$\begin{array}{lll}12 & \tau \mathrm{SH} & 2.35 \\ 16 & \rho \mathrm{NH}_{2} & 1.83 \\ 17 & \rho \mathrm{NH}_{2} & 1.11 \\ & \text { Total } & 13.29\end{array}$

0.17 
Table 6 (continued)

$$
\text { Form } 1
$$

$$
\begin{aligned}
& \omega \\
& \left(\mathrm{cm}^{-1}\right)
\end{aligned}
$$

$\left(\mathrm{cm}^{-1}\right) \quad(\mathrm{km} / \mathrm{mol})$

6

Gln

252

237

185

30
73

$7 \quad$ Glu

$\begin{array}{ll}234 & 38 \\ 608 & 92 \\ 946 & 143\end{array}$

8

$\begin{array}{lll}\text { Gly } & 234 & 43 \\ & 666 & 88 \\ & 961 & 138\end{array}$

$9 \quad$ His 508

$\begin{array}{ll}508 & 61 \\ 329 & 23 \\ 648 & 86\end{array}$

$10 \quad$ Ile

$\begin{array}{ll}245 & 19 \\ 260 & 14 \\ 630 & 74\end{array}$

19
14
74

(n)

$\begin{array}{lll}\rho \mathrm{NH}_{2} & 2.85 & \\ \rho \mathrm{NH}_{2} & 1.89 & \\ \tau \mathrm{OH} & 1.67 & \\ \text { Total } & 16.26 & 0.18\end{array}$

$\begin{array}{lll}\omega \mathrm{NH}_{2} & 26.28 & \\ \rho \mathrm{NH}_{2} & 4.75 & \\ \tau \mathrm{OH} & 1.81 & \\ \text { Total } & 45.72 & 0.50 \\ & & \\ \rho \mathrm{NH}_{2} & 6.24 & \\ \tau \mathrm{OH} & 2.24 & \\ \omega \mathrm{NH}_{2} & 1.43 & \\ \text { Total } & 23.23 & 0.27 \\ & & \\ \rho \mathrm{NH}_{2} & 7.02 & \\ \tau \mathrm{OH} & 1.77 & \\ \omega \mathrm{NH}_{2} & 1.34 & \\ \text { Total } & 17.66 & 0.40\end{array}$

Form 2

$\omega$ $\left(\mathrm{cm}^{-1}\right)$

$\begin{array}{llll}\mathrm{I}_{\mathrm{IR}}(\mathrm{km} / \mathrm{mol}) & \operatorname{mode}^{\mathrm{a}} & <\alpha^{\mathrm{v}}> & <\alpha^{\mathrm{v}}>/<\alpha^{\mathrm{e}}> \\ 15 & \mathrm{\rho} \mathrm{NH}_{2} & 1.63\end{array}$


Table 6 (continued)

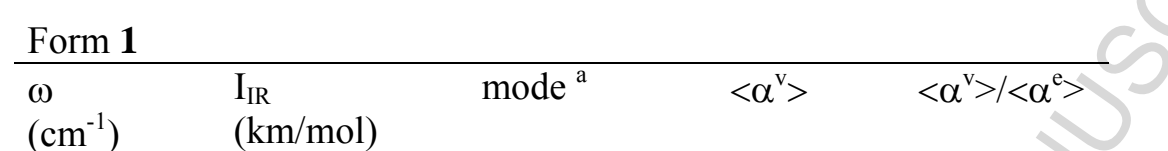

Form 2

$\omega \quad \mathrm{I}_{\mathrm{IR}}(\mathrm{km} / \mathrm{mol}) \quad \operatorname{mode}^{\mathrm{a}} \quad\left\langle\alpha^{\mathrm{v}}\right\rangle \quad\left\langle\alpha^{\mathrm{V}}>/\left\langle\alpha^{\mathrm{e}}\right\rangle\right.$

11 Leu $\begin{array}{r}245 \\ 627 \\ 321\end{array}$

$245 \quad 30 \quad-56 \mathrm{NH}_{2}-4.44$

$\begin{array}{ll}245 & 30 \\ 627 & 86 \\ 321 & 12\end{array}$

12 Lys

$\begin{array}{ll}244 & 30 \\ 310 & 36 \\ 629 & 96\end{array}$

96

13 Met $\quad 228$

$\begin{array}{ll}228 & 19 \\ 624 & 99\end{array}$

253

15

$\begin{array}{lll}14 \quad \text { Phe } \quad 322 & 29 \\ & 257 & 13 \\ 649 & 66\end{array}$

$\begin{array}{ll}\rho \mathrm{NH}_{2} & 4.44 \\ \tau \mathrm{OH} & 1.95 \\ \rho \mathrm{NH}_{2} & 1.05 \\ \text { Total } & 15.62\end{array}$

$\left(\mathrm{cm}^{-1}\right)$

$294 \quad 21$

\section{6}

1453

17
215

0.17

$\rho \mathrm{NH}_{2}$

$\rho \mathrm{NH}_{2}$

4.58

$\tau \mathrm{OH}$

3.36

Total

2.17

22.16

0.21

$\begin{array}{ll}\rho \mathrm{NH}_{2} & 3.32 \\ \tau \mathrm{OH} & 2.27 \\ \rho \mathrm{NH}_{2} & 2.16 \\ \text { Total } & 16.62\end{array}$

3.32
2.27

2.16
16.62

0.16

306

306
889

889
266

176

13

$\begin{array}{ll}\mathrm{NH}_{2} & 2.49\end{array}$

$\rho \mathrm{NH}_{2} \quad 1.75$

$\tau \mathrm{OH} \quad 1.40$

Total

15.55

0.13

\section{1}

1438

334

17

17
416

16

291

1428

865

18

406

76

$\begin{array}{ll}\tau \mathrm{OH} & 1.64 \\ \delta \mathrm{OH} & 1.18 \\ \nu \mathrm{NH}--\mathrm{O} & 1.05 \\ \text { Total } & 10.86\end{array}$

366

215

$\begin{array}{ll}1144 & 172 \\ 431 & 22\end{array}$

22

Total

10.86

0.14

$\begin{array}{ll} & \\ \rho \mathrm{NH}_{2} & 2.16 \\ \nu \mathrm{OH}-\mathrm{N} & 1.26 \\ \delta \mathrm{OH} & 0.91 \\ \text { Total } & 10.07 \\ & \\ \rho \mathrm{NH}_{2} & 3.64 \\ \omega \mathrm{NH}_{2} & 2.00 \\ \rho \mathrm{NH}_{2} & 1.67 \\ \text { Total } & 17.78 \\ & \\ \rho \mathrm{NH}_{2} & 1.91 \\ \delta \mathrm{OH} & 1.80 \\ \nu \mathrm{OH}-\mathrm{N} & 1.28 \\ \text { Total } & 11.31 \\ & \\ \rho \mathrm{NH} & \\ \delta \mathrm{OH} & 1.92 \\ \tau \text { OH } & 1.78 \\ \text { Total } & 0.92 \\ & 11.56 \\ \nu \text { OH--N } & 1.28 \\ \tau \text { ring } & 1.05 \\ \delta \text { OH } & 1.02 \\ \text { Total } & 9.03\end{array}$

0.11

0.09

$\begin{array}{lll}19 & v \text { OH--N } & 1.28 \\ 5 & \tau \text { ring } & 1.05 \\ 240 & \delta \text { OH } & 1.02 \\ & \text { Total } & 9.03\end{array}$


Table 6 (continued)

\begin{tabular}{|c|c|c|c|c|c|c|c|c|c|c|c|}
\hline & & Form 1 & & & & & Form 2 & & & & \\
\hline & & $\begin{array}{l}\omega \\
\left(\mathrm{cm}^{-1}\right)\end{array}$ & $\begin{array}{l}\mathrm{I}_{\mathrm{IR}} \\
(\mathrm{km} / \mathrm{mol})\end{array}$ & mode $^{a}$ & $\left\langle\alpha^{\mathrm{v}}\right\rangle$ & $\left\langle\alpha^{v}\right\rangle$ & $\omega$ & $\mathrm{I}_{\mathrm{IR}}(\mathrm{km} / \mathrm{mol})$ & mode $^{a}$ & $\left\langle\alpha^{\mathrm{v}}\right\rangle$ & $\left\langle\alpha^{\mathrm{v}}>/\left\langle\alpha^{\mathrm{e}}\right\rangle\right.$ \\
\hline 16 & Ser & 246 & 88 & $\tau \mathrm{OH}$ & 13.08 & & 636 & 110 & $\tau \mathrm{OH}$ & 2.44 & \\
\hline & & 267 & 30 & $\rho \mathrm{NH}_{2}$ & 3.73 & & 1440 & 508 & $\delta \mathrm{OH}$ & 2.20 & \\
\hline & & 314 & 27 & $\rho \mathrm{NH}_{2}$ & 2.42 & & 304 & 19 & $\rho \mathrm{NH}_{2}$ & 1.82 & \\
\hline & & & & Total & 30.87 & 0.51 & & & Total & 16.63 & 0.28 \\
\hline 17 & Thr & 261 & 100 & $\tau \mathrm{OH}$ & 13.16 & & 214 & 55 & $\tau \mathrm{OH}$ & 10.74 & \\
\hline & & 244 & 33 & $\rho \mathrm{NH}_{2}$ & 5.03 & & 1457 & 441 & $\delta \mathrm{OH}$ & 1.86 & \\
\hline & & 655 & 106 & $\tau \mathrm{OH}$ & 2.22 & & 370 & 28 & $v$ OH--N & 1.86 & \\
\hline & & & & Total & 32.56 & 0.45 & & & Total & 24.00 & 0.33 \\
\hline 18 & $\operatorname{Trp}$ & 361 & 39 & $\rho \mathrm{NH}_{2}$ & 2.69 & & 287 & 23 & $\rho \mathrm{NH}_{2}$ & 2.48 & \\
\hline & & 506 & 64 & $\delta \mathrm{OH}$ & 2.25 & & 1438 & 452 & $\delta \mathrm{OH}$ & 1.96 & \\
\hline & & 411 & 32 & $\gamma \mathrm{NH}$ & 1.68 & & 428 & 38 & $\gamma \mathrm{NH}$ & 1.86 & \\
\hline & & & & Total & 21.89 & 0.14 & & & Total & 19.40 & 0.12 \\
\hline 19 & Tyr & 367 & 95 & $\tau \mathrm{OH}$ & 6.36 & & 364 & 96 & $\tau \mathrm{OH}$ & 6.51 & \\
\hline & & 330 & 21 & $\rho \mathrm{NH}_{2}$ & 1.74 & & 1436 & 395 & $\delta \mathrm{OH}$ & 1.72 & \\
\hline & & 257 & 12 & $\rho \mathrm{NH}_{2}$ & 1.64 & & 285 & 12 & $\rho \mathrm{NH}_{2}$ & 1.34 & \\
\hline & & & & Total & 25.20 & 0.19 & & & Total & 22.05 & 0.17 \\
\hline 20 & Val & 219 & 13 & $\rho \mathrm{NH}_{2}$ & 2.43 & & 289 & 20 & $\rho \mathrm{NH}_{2}$ & 2.12 & \\
\hline & & 275 & 19 & $\rho \mathrm{NH}_{2}$ & 2.26 & & 1442 & 340 & $\delta \mathrm{OH}$ & 1.47 & \\
\hline & & 248 & 11 & $\rho \mathrm{NH}_{2}$ & 1.58 & & 338 & 13 & v OH--N & 1.00 & \\
\hline & & & & Total & 16.61 & 0.21 & & & Total & 10.26 & 0.13 \\
\hline
\end{tabular}

${ }^{a} \rho=$ rocking, $\gamma=$ bending, $\delta=$ bending, $\tau=$ torsion, $v=$ stretching, $\omega=$ wagging 
Figure captions

\begin{tabular}{|c|c|}
\hline Fig. 1 & Backbone conformations of the studied amino acids. \\
\hline Fig. 2 & $\begin{array}{l}\text { Calculated vs experimental }\left(\mathrm{H}_{2} \mathrm{O}\right) \text { electronic dipole polarizabilities of amino } \\
\text { acids.Triangles refer to a mean }\left\langle\alpha^{\mathrm{e}}>\text { value of } \mathbf{1} \text { and } \mathbf{2} \text { forms, circles refer to the }\right. \\
\text { zwitterionic form. B97-1/aug-cc-pVDZ results. }\end{array}$ \\
\hline Fig. 3 & $\begin{array}{l}\text { Mean electronic dipole polarizability of amino acid } \mathbf{1} \text { and } \mathbf{2} \text { forms as a function of the } \\
\text { molecular volume. The computed volume corresponds to the } 0.001 \text { a.u. density } \\
\text { contour. }\left\langle\alpha^{\mathrm{e}}\right\rangle(0 ; 0)=0.09 \mathrm{~V}-16.99, \mathrm{r}^{2}=0.95 \text {. B97-1/aug-cc-pVDZ results. }\end{array}$ \\
\hline Fig. 4 & $\begin{array}{l}\text { Relation between mean electronic dipole polarizability and number of electrons of } \\
\text { amino acid } 1 \text { and } 2 \text { forms. }<\alpha^{\mathrm{e}}>(0 ; 0)=1.64 Z-29.03, \mathrm{r}^{2}=0.95 . \text { B97-1/aug-cc-pVDZ } \\
\text { results. }\end{array}$ \\
\hline Fig. 5 & $\begin{array}{l}\text { Relation between mean electronic dipole polarizability of amino acid } 1 \text { and } 2 \text { forms and } \\
\text { the sum of atomic contributions. }<\alpha^{\mathrm{e}}>(0 ; 0)=0.75 \Sigma_{\mathrm{i}}<\alpha^{\mathrm{e}}>_{\mathrm{i}}(0 ; 0)-7.71, \mathrm{r}^{2}=0.96 . \\
\text { Mean atomic polaizabilities (a.u.). } \mathrm{H}: 4.60 ; \mathrm{N}: 7.00 ; \mathrm{C}: 11.72 ; \mathrm{O}: 4.57 ; \mathrm{S}: 18.47 \text {. } \\
\text { B97-1/aug-cc-pVDZ results. }\end{array}$ \\
\hline Fig. 6 & $\begin{array}{l}\text { Relation between mean electronic dipole polarizability of amino acid } \mathbf{1} \text { and } 2 \text { forms and } \\
\text { molecular hardness. }<\alpha^{\mathrm{e}}>(0 ; 0)=-49.73 \eta+367.91, \mathrm{r}^{2}=0.84 \text {. B97-1/aug-cc-pVDZ } \\
\text { results. }\end{array}$ \\
\hline
\end{tabular}



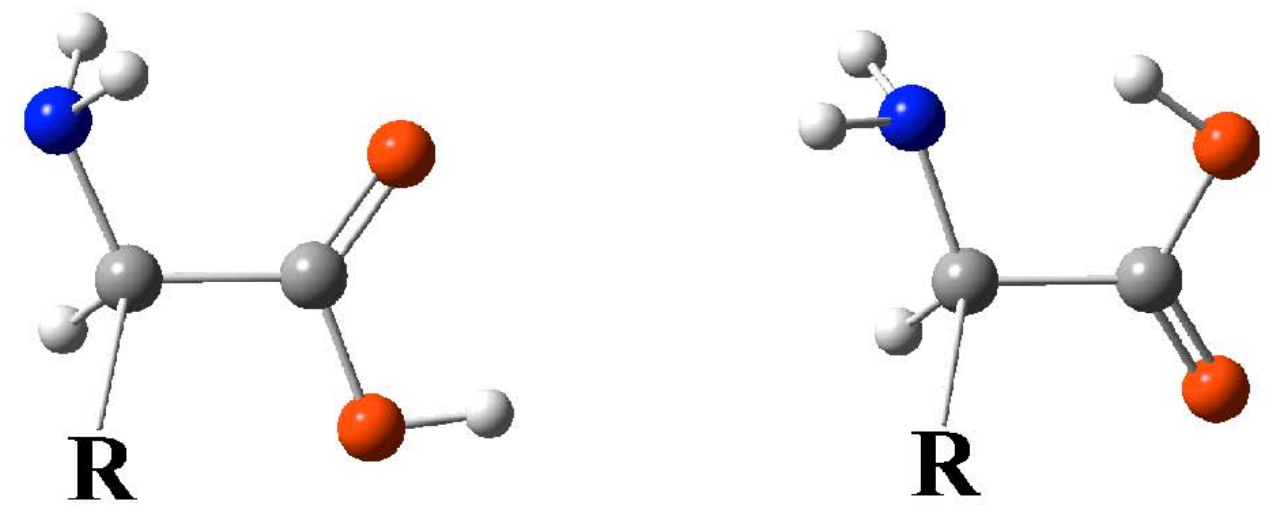

1

2

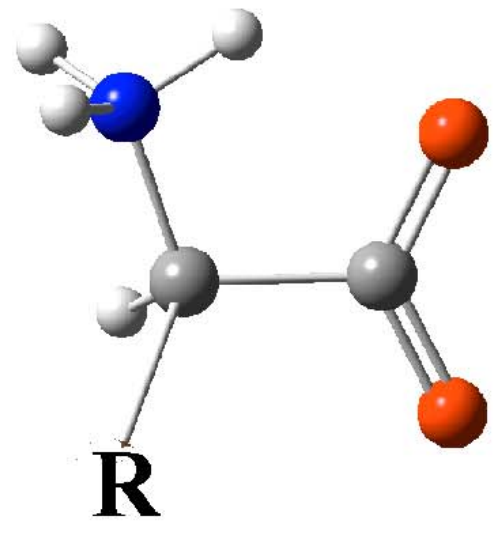

Fig. 1 


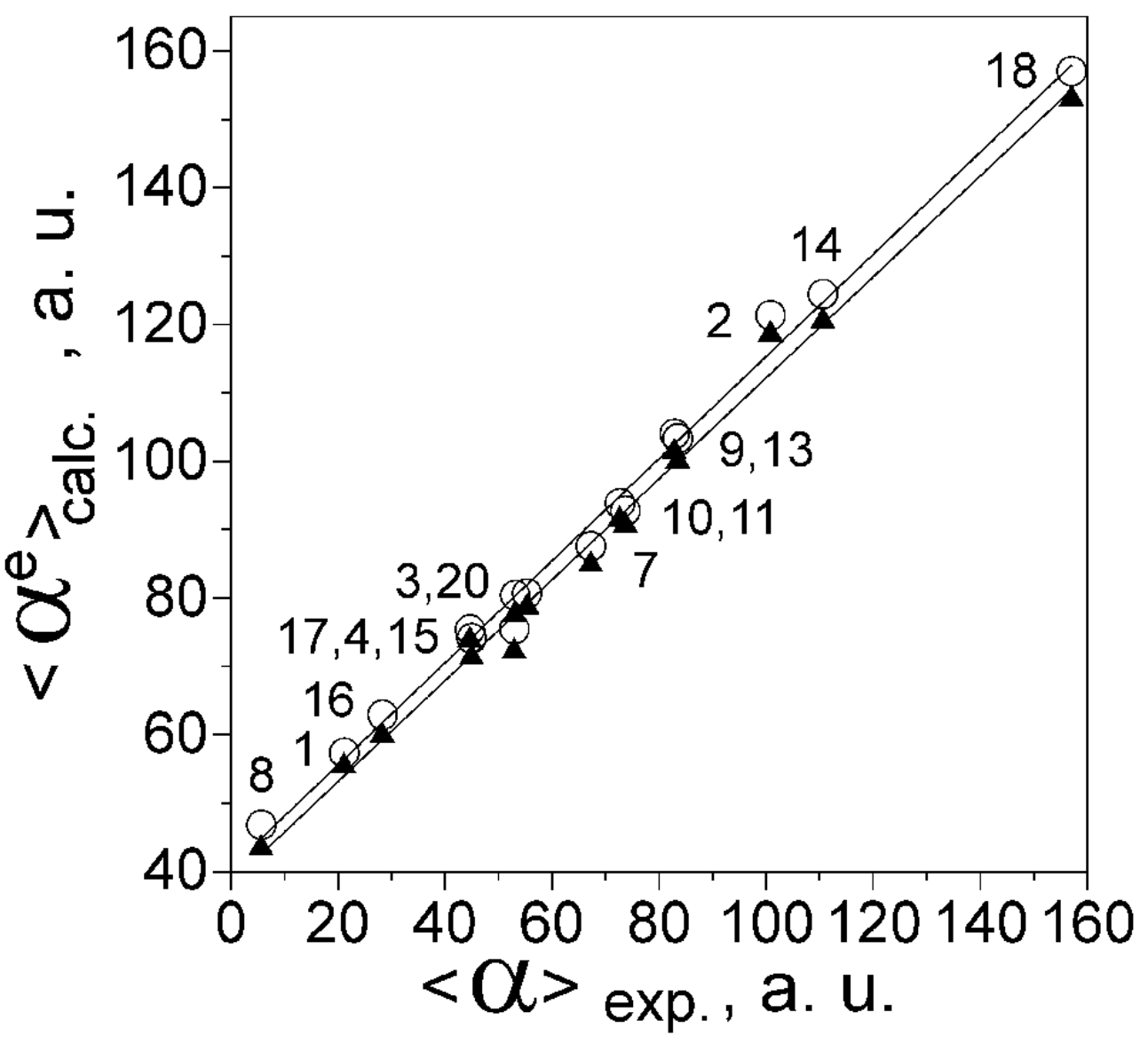

Fig. 2 


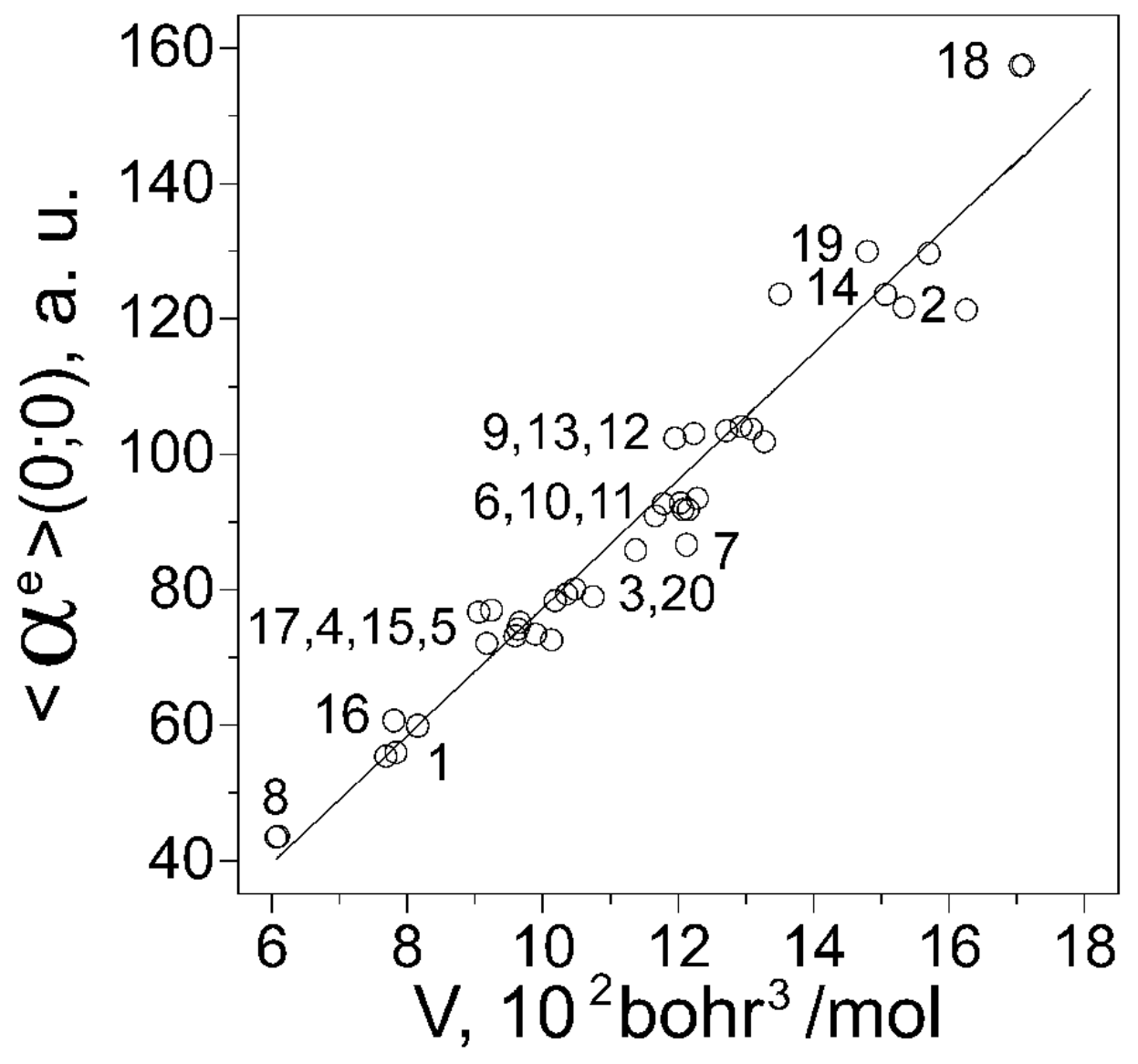

Fig. 3 


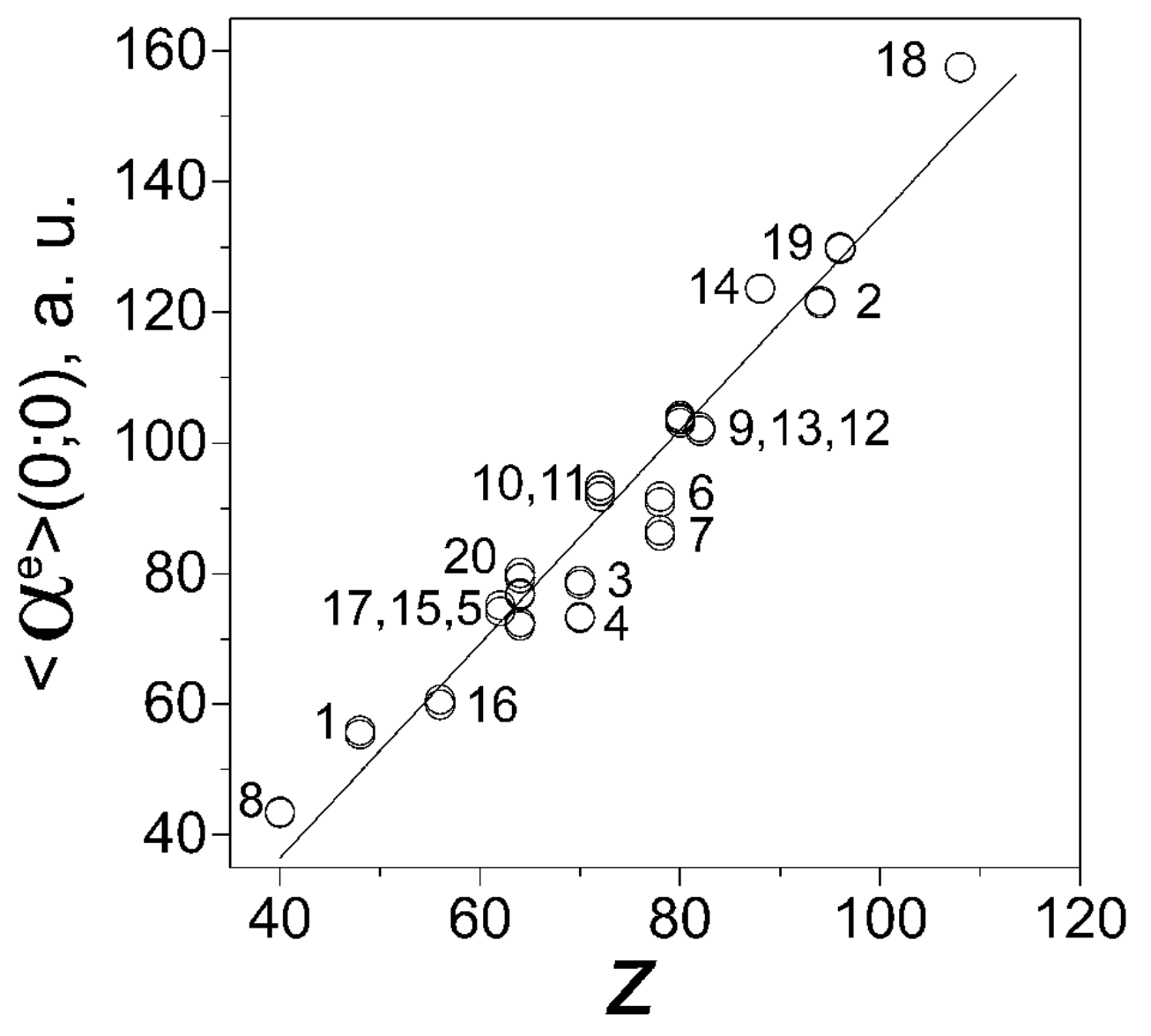

Fig. 4 


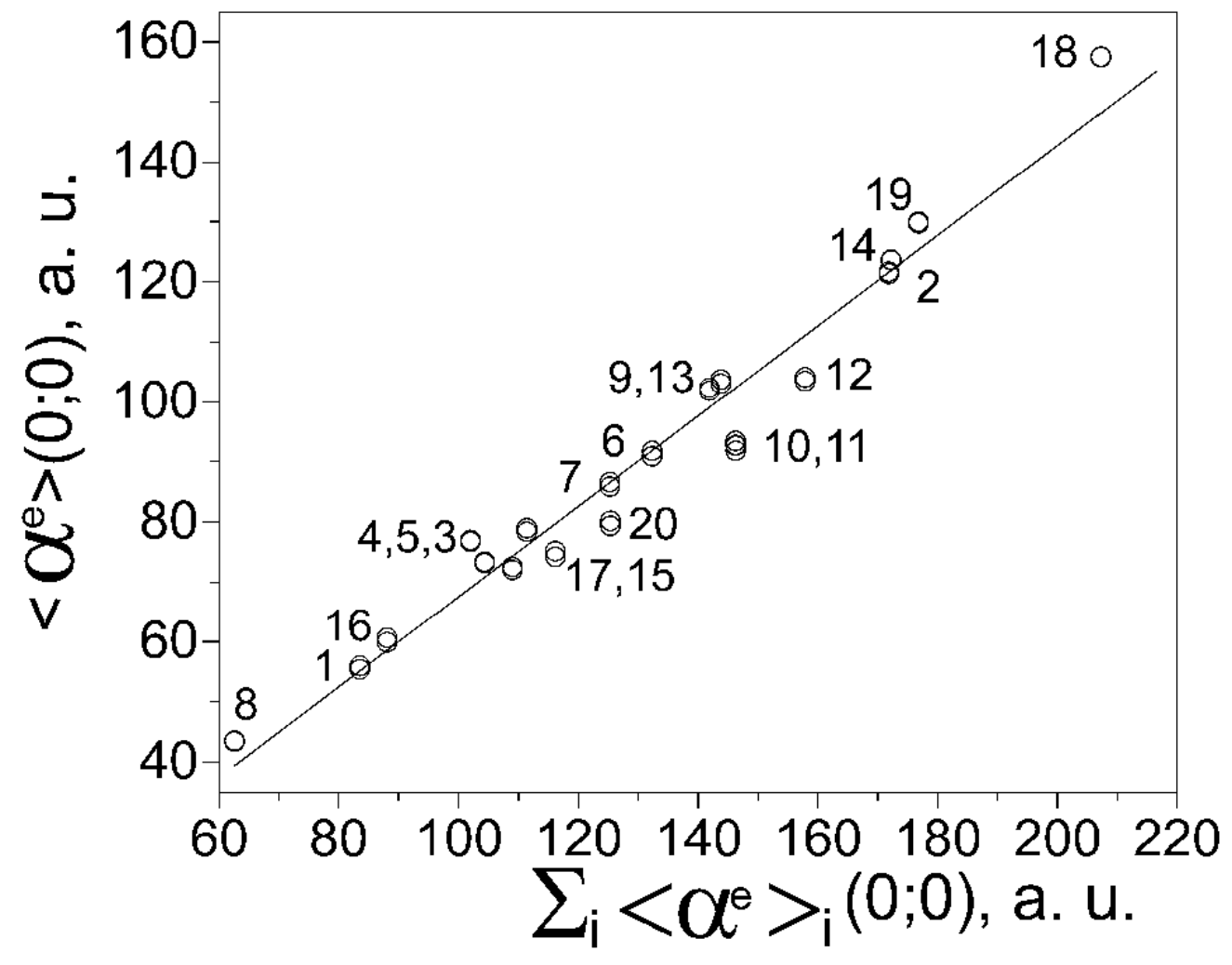

Fig. 5 


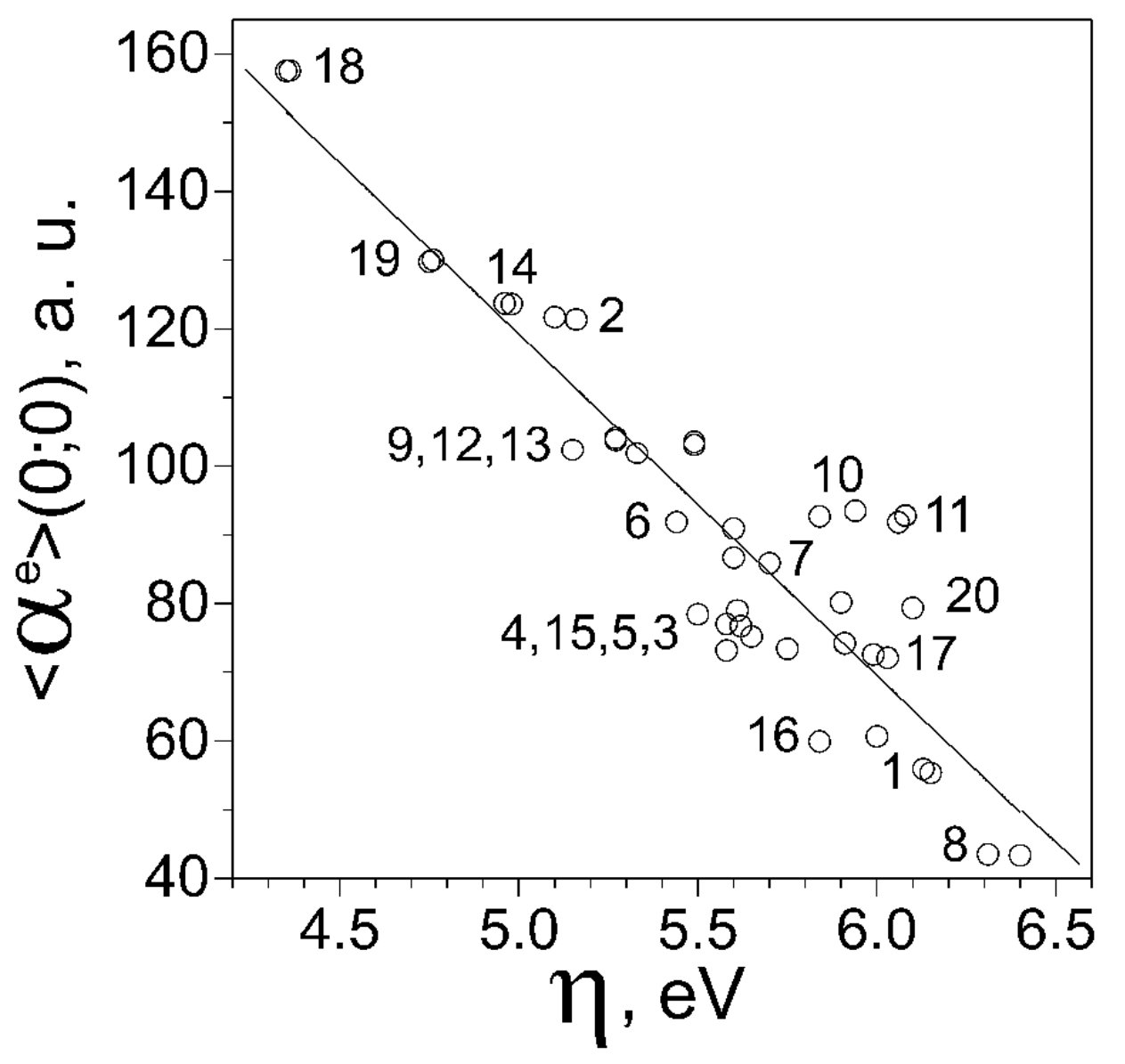

Fig. 6 